Research Article

\title{
Exploration of Normal Stochastic Multicriteria Decision-Making and Legal Dilemma in Project Investment
}

\author{
Jianmiao Hu' ${ }^{1}$ and Chong Chen (iD) ${ }^{2}$ \\ ${ }^{1}$ School of Transportation Management, Zhejiang Institute of Communications, Hangzhou, Zhejiang, China \\ ${ }^{2}$ Zhejiang University of Technology, Hangzhou, Zhejiang, China \\ Correspondence should be addressed to Chong Chen; gdcc@zjut.edu.cn
}

Received 6 August 2021; Accepted 17 September 2021; Published 19 November 2021

Academic Editor: Zaoli Yang

Copyright (c) 2021 Jianmiao Hu and Chong Chen. This is an open access article distributed under the Creative Commons Attribution License, which permits unrestricted use, distribution, and reproduction in any medium, provided the original work is properly cited.

\begin{abstract}
The purpose is to help enterprise managers make more accurate, scientific, and objective decisions on the optimal supplier in project investment, improve investment return and overall efficiency, and reduce investment risk. Following an introduction of normal stochastic multicriteria decision-making, a normal stochastic multicriteria decision-making method is proposed based on Bayesian Network- (BN-) Technique for Order Preference by Similarity to an Ideal Solution (TOPSIS) to help investors select suppliers. First, product cost, product quality, and product service are selected as evaluation indexes, and then, a supplier evaluation model is built based on the BN concept for expert evaluation. Second, the evaluation information is integrated. Based on the TOPSIS normal stochastic multicriteria decision-making method, the optimal supplier is selected under the comparison of the fit degree between each supplier and the best and worst solution. Finally, the optimal solution is determined and verified by a simulation example. The results show that in the problem of supplier selection in the retail industry, the BN model can truly provide feedback the product quality, cost, and service situation of each supplier and fully consider their behavior diversity. The normal stochastic multicriteria decision-making method based on TOPSIS can select the suppliers that are most in line with the investors' development goals, especially in the face of good and bad suppliers. BN-based TOPSIS normal stochastic multicriteria decision-making method has strong logic and efficiency, is easy to operate, and has high practical value. Furthermore, the relevant laws of project investment decision-making are discussed through consultation on the relevant literature, thus providing help for the construction of relevant laws in the future.
\end{abstract}

\section{Introduction}

Simply, the project investment decision-making is an investment plan made for investment and investment return [1]. In practice, to maximize the investment return, investors often adopt scientific and reasonable ways to conduct a full investigation, analysis, and demonstration on such factors as investment projects, investment scale, and investment direction, and make the judgment and formulate the investment plan accurately and perfect $[2,3]$. The most important business of investment enterprises is project investment, while investment decision-making is the most important factor to the success of the enterprise, whose scientificity and reasonableness determine the continuous increase of enterprise benefits [4].
Under the rapid economic development and fierce market competition, many problems have occurred in the investment industry in China, and investors are often blindly confident. Therefore, most of the investment decisions lack scientific rationality, which is believed to be caused by two reasons: first, the investment heat is driven by the Unicorn project; some investors have a strong momentum of development depending on their unique advantages, become unicorns in this field to obtain huge profits, and attract the favor of other investors who will eventually join them; investors' such reckless behavior, which often lacks the consideration of self-factors, undoubtedly increases the risk of investment decision-making. Second, blind confidence is brought by the emerging industries to investors. In the face 
of emerging industry investment, many investors in traditional industries are overconfident. Once there is financing demand in an emerging industry, investors will rush in and make decisions without scientific analysis [5].

With the continuous development and improvement of the management field, decision-making is being affected by some single factors (criterion), as well as many interrelated and restrictive factors (criterion). In particular, decision makers often have to consider all these factors (criterion) as much as possible to make accurate and reliable decisions, namely the multicriteria decision-making problem [6]. In practice, many factors can affect decision-making in project investments, such as suppliers' cost control ability, overall product quality, and product-related services. These multicriteria decision-making problems often involve random variables due to the complexity and uncertainty of the situation. Studies have found that the random variables obey or approximately obey the normal distribution, and the criterion is the multicriteria decision-making of random variables that obey the normal distribution, namely, the normal random multicriteria decision-making [7]. To date, enterprises still cannot solve many multicriteria decision-making problems in actual project investments. It is imperative for enterprises to make accurate and scientific decisions under uncertainty [8]. Bayesian Network $(\mathrm{BN})$ has a strong antiuncertainty ability using conditional probability to express the correlation between various information elements; it can learn and reason under limited, incomplete, and uncertain information conditions. BN can be used to comprehensively evaluate the reliability of suppliers [9]. Technique for Order Preference by Similarity to an Ideal Solution (TOPSIS) is a sort method by approximating the ideal solution; its basic principle reads: first, the initial data matrix is normalized to find out the best scheme and the worst scheme, then the distance is calculated between each alternative scheme and the best scheme and the worst scheme and is sorted by the proximity of each alternative scheme to the best scheme, and the best scheme is found out among the alternatives [10]. BN TOPSIS method can be used for enterprise project investment to help managers make accurate, scientific, and objective decisions on the optimal supplier, and it plays an important role in improving investment return, overall efficiency, and reducing investment risk.

In the process of project investment decision-making, there are more and more problems caused by the lack of laws. The main reasons are as follows: first, there is no legal reference for decision-making due to the lack of relevant laws $[11,12]$. At present, the laws for project investment decision-making in China are only written in the government's policy documents, without forming a system of rules and regulations. As a result, the legal base for investment decisions is lacking, so investors often make decisions only from the income without the corresponding approval process $[13,14]$. Meanwhile, the existing policy provisions are not implemented effectively [15]. Even under strict requirements, policy loopholes can be found by some speculators.

Thereupon, the purpose is to solve the investment problem and ensure the feasibility, scientificity, and rationality of project investment decision-making. Here, the BN-based TOPSIS normal stochastic multicriteria decisionmaking method is used to evaluate the retail industry suppliers and analyze their reliability, thereby help investors select suppliers and make more scientific investment decisions in the complex economic environment. Shortly, the results have some theoretical and reference significance for future project investment decision-making and law-making research and have certain application prospects and economic value. This research aims to provide an important reference for the comprehensive evaluation of optimal suppliers in the process of enterprise project investment, the decision-making, and the construction of relevant laws in the future.

\section{Theory and Method}

2.1. Normal Stochastic Multicriteria Decision Theory. Gaussian distribution is a very important continuous probability distribution with the characteristics of random variables in mathematics and is also called normal distribution, which literally means the most obvious probability distribution. In practical problems, the probability distribution of many random variables is found to be in the form of normal distribution, because of which normal distribution is widely used in the field of science and engineering. The normal distribution probability curve is called the bell curve because of its symmetry of being low on both sides and high in the middle. In practical applications, Sun believed that the outbreak of plague and its change with time approximately followed the normal distribution and used this function for research as a reference for actual epidemic prevention work [16]. Liu et al. thought that the amount of fertilizer used in rice was normally distributed and used the theory to study the implementation effect of fertilizer in rice [17]. Ye et al. applied normal distribution to study the ornamental characters of different species of cut chrysanthemum [18]. In daily life, there are also phenomena, such as product quality, company sales volume, income, and investment, in which the random variables involved follow or roughly follow the normal distribution [19-21].

With the development of project investment decisionmaking management, the influence of a single factor should be considered, along with the influence of interrelated and mutual restricting factors for project investment decisionmaking. To improve the reliability of decision-making, investors should often consider all factors (factors are also called criteria), the process of which is usually called multicriteria decision-making $[22,23]$. The criterion of multicriteria decision-making approximately conforms to the normal distribution in reality. The decision information obtained by multicriteria decision-making is aggregated with specific methods, and the schemes are sorted according to the corresponding rules, from which the best scheme is selected according to the results. Decision information generally includes criteria, criteria weight, and subjective preference. More scholars are focusing on the practical problems of normal random variables and have made implementable achievements [24, 25]. 
Generally, in terms of the analysis on the practical problems of normal stochastic multicriteria decision-making, the scheme set of a multicriteria decision-making problem is assumed to be $A=\left\{A_{1}, A_{2}, \ldots, A_{m}\right\}$, and the criterion set is $C=\left\{c_{1}, c_{2}, \ldots, c_{n}\right\}$, based on which the multicriteria decision-making model is established, as shown in Table $1 . b_{i j}(i=1,2, \ldots, m ; j=1,2, \ldots, n)$ is the value of the scheme $A_{i}$ under the criterion $c_{j}$.

The problem-solving process of the multicriteria decision-making model is shown in Figure 1.

\subsection{Supplier Evaluation Model Based on BN. BN is a} probability network, also known as causal network, which is a widely used mathematical model based on probability theory and can digitally present strong logical reasoning problems through calculation [26]. In short, Bayesian is a vector acyclic graph, which can show the relationship between variables intuitively and systematically and reduce the difficulty of information decision processing [27]. The nodes in the vector acyclic graph can indicate random variables, and the relationship between random variables is represented by directed line segments. The expression reads as follows:

$$
B N=|G(I, E), P| .
$$

In equation (1), $G(I, E)$ represents a vector acyclic graph, in which $I$ denotes the set of nodes, and $E$ indicates the vector set between nodes; $P$ stands for the joint probability distribution. If $X=\left(X_{i}\right), i \in I$ is a random variable node $i$, then equation (2) is obtained.

$$
P(X)=\sum_{i \in I} P\left(X_{i} \mid X_{\mathrm{pa}(i)}\right) .
$$

In equation (2), $\mathrm{pa}(i)$ represents the factor of the random variable $i$. If the number of random variables is large, the expression reads as follows:

$$
P\left(X_{1}, X_{2}, \ldots, X_{n}\right)=P\left(X_{n} \mid X_{1}, X_{2}, \ldots, X_{n-1}\right) \cdots P\left(X_{2} \mid X_{1}\right) P\left(X_{1}\right) .
$$

The simple BN structure is shown in Figure 2, where $a 4$ depends on $a 1, a 2$, and $a 3$ and $a 1, a 2$, and $a 3$ have no parent nodes, then $P\left(a_{3}\right)=P\left(a_{4} \mid a_{3}, a_{2}, a_{1}\right) P\left(a_{3}\right) P\left(a_{2}\right) P\left(a_{1}\right)$.

Here, when the supplier evaluation model is built with $\mathrm{BN}$, cost, service, and revenue are selected as evaluation indexes. The corresponding network structure is shown in Figures 3-5, respectively.

The selection basis of each evaluation index is as follows.

2.2.1. Product Cost. Cost refers to the total expenditure of an enterprise for manufacturing and selling a specific number of products within a specific period of time, which can directly affect the profit of the enterprise and is one of the important factors in supplier evaluation. The cost item includes purchase, distribution, and waste costs. Specifically, the purchase cost of a supplier includes the total price of goods, procurement, and other related expenses, which are related to the customer's demand and the unit price of products. Distribution is an important operation link of suppliers. Distribution cost refers to all the inevitable expenses of suppliers in product distribution. According to the actual situation, the distribution cost is determined by customers' personalized needs, distribution distance, and distribution modes. Waste costs may occur during enterprise operation due to improper management, such as redundant personnel, excess inventory, and large material consumption in production, which will increase the total expenditure of the enterprise and reduce enterprise profit. Thus, waste cost directly affects the enterprise management quality.

2.2.2. Product Quality. Product quality refers to the collection of the product features and performance to meet the specified needs and potential needs. Any product is manufactured to meet the needs of users. Product quality is an important index to measure the competitiveness of suppliers. Product quality affects the market price of products and the reputation of enterprises. It is the lifeline of enterprises. The supplier's product manufacturing is mainly divided into new product production, product recycling and storage, and remanufacturing of wasted and expired products. Therefore, the quality item includes three parts: new product quality, inventory product quality, and recycled product quality. The quality of new products is the basis for enterprise operation, profit acquisition, and sound reputation; generally, inventory products can induce losses if not handled properly. Thus, there is a need to pay attention to the quality monitoring of inventory products. Remanufacturing wasted and expired products can save material costs, which is also another form of new product manufacturing that needs considerable quality monitoring. In short, these three product quality indexes are important assessment bases for supplier reliability.

2.2.3. Product Service. The purpose of product services is to enhance user experience and improve customer satisfaction. Suppliers with strong service awareness, good service attitude, and high service quality help improve the utilization value of goods, and good service, in turn, can also strengthen the partnership between retailers and suppliers. The service items are mainly divided into three parts: presales service, insales service, and after-sales service. Presales service refers to a series of services, such as providing information, online and offline consultation, and market research and prediction before customers contact the products; it plays an important role in collecting customer data, retaining customers, and expanding the enterprise market. In-sales service is provided to customers in the process of product sales, which is an activity to deeply understand customers' needs and assist them in purchasing the most appropriate products; the quality of in-sales service is a crucial factor of customer's purchase intention. After-sales service refers to various service activities provided following the sold goods or products, the more thoughtful the after-sales service is, the higher the service level of the supplier is; enterprises can 
TABle 1: Multicriteria decision matrix model.

\begin{tabular}{|c|c|c|c|c|}
\hline \multirow{2}{*}{ Programs } & \multicolumn{4}{|c|}{ Criteria } \\
\hline & $c_{1}$ & $c_{2}$ & $\ldots$ & $c_{n}$ \\
\hline$A_{1}$ & $b_{11}$ & $b_{12}$ & $\ldots$ & $b_{1 n}$ \\
\hline$A_{2}$ & $b_{21}$ & $b_{22}$ & $\ldots$ & $b_{2 n}$ \\
\hline$\cdots$ & $\ddot{b}_{m 1}$ & $\ddot{b}_{m 2}$ & $\begin{array}{l}\cdots \\
\ldots \\
\end{array}$ & $\cdots$ \\
\hline
\end{tabular}

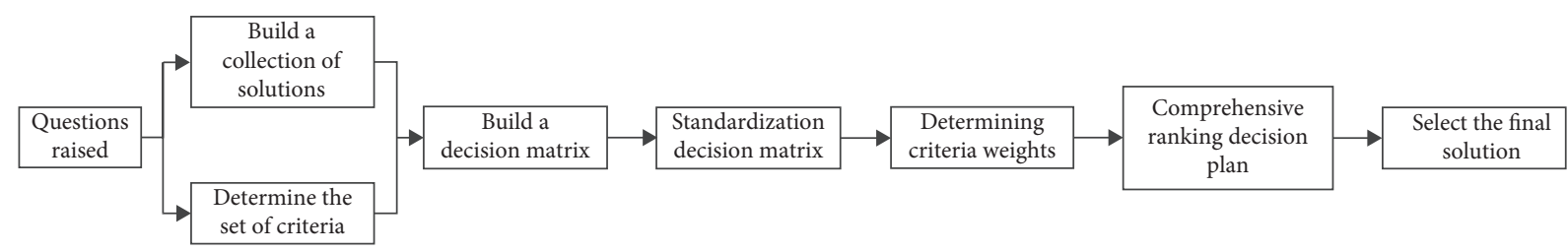

FIgURE 1: Multicriteria decision-making process.

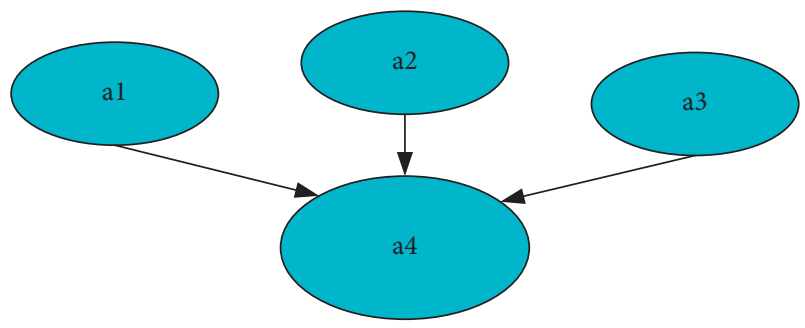

FIgURE 2: Simple BN structure.

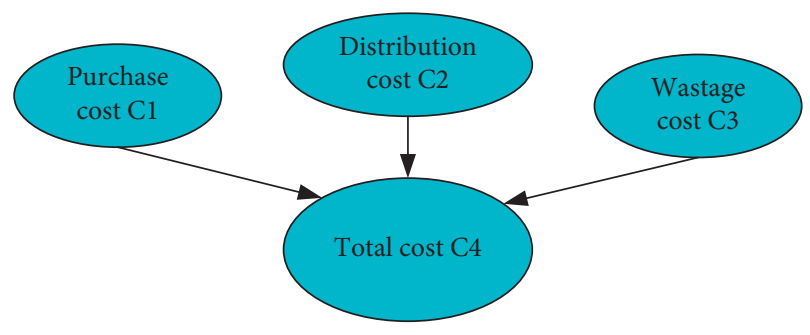

Figure 3: BN cost structure.

improve their reputation and expand their market share through excellent after-sales service.

After the construction of the network structure, the parameters are set. First, cost parameters setting: The cost approximately obeys the normal distribution, and the cost probability $P\left(C_{4}\right)$ reads as follows:

$$
P\left(C_{4}\right)=P\left(C_{4} \mid C_{3}, C_{2}, C_{1}\right) P\left(C_{3}\right) P\left(C_{2}\right) P\left(C_{1}\right) .
$$

Similarly, according to the requirements of investors, the quality probability $P\left(Q_{4}\right)$ reads as follows:

$$
P\left(Q_{4}\right)=P\left(Q_{4} \mid Q_{3}, Q_{2}, Q_{1}\right) P\left(Q_{3}\right) P\left(Q_{2}\right) P\left(Q_{1}\right) .
$$

According to the consumer satisfaction survey, the service probability $P\left(S_{4}\right)$ reads as follows:

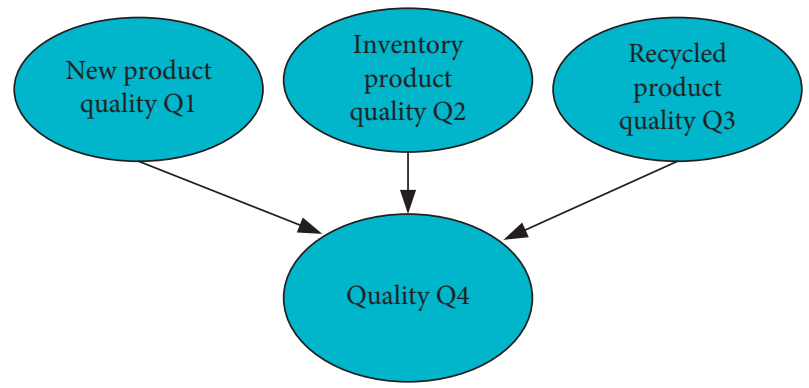

FIgURE 4: BN quality structure.

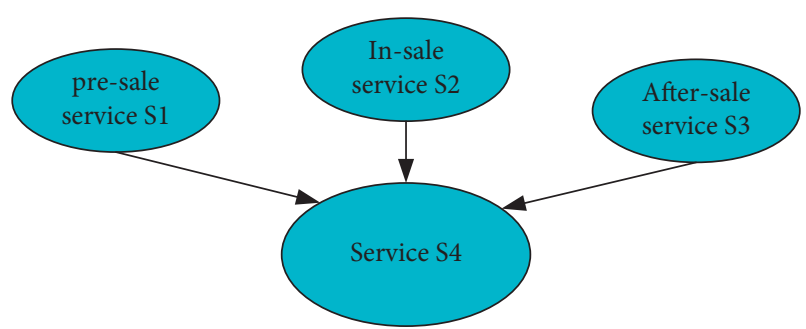

FIGURE 5: BN service structure.

$$
P\left(S_{4}\right)=P\left(S_{4} \mid S_{3}, S_{2}, S_{1}\right) P\left(S_{3}\right) P\left(S_{2}\right) P\left(S_{1}\right) .
$$

2.3. Normal Stochastic Multicriteria Decision-Making Based on TOPSIS. TOPSIS is a ranking method proposed by C. L. Hwang and K. Yoon in 1981, which is based on the degree of fit between the evaluation object and the ideal target. Its essence is to sort the evaluation object through distance calculation and analysis between the evaluation object and the optimal solution and between the evaluation object and the worst solution. If the evaluation object is closest to the 
optimal solution and farthest away from the worst solution, the result is the best; otherwise, the result is not optimal. Each index of the optimal solution reaches the optimal value of each evaluation index. Each index value of the worst solution reaches the worst value of each evaluation index. Since its proposal, the TOPSIS method has been used in the field of multicriteria decision-making, has also been widely expanded, and is distinguished according to different classification standards. For example, according to the number of decision-making experts, the TOPSIS method can be divided into individual decision-making and group decision-making; according to the attribute and weight of criterion, it can be divided into interval type, fuzzy type, and mixed type. In practice, TOPSIS is applied to specific issues, such as brand valuation, risk assessment, and importance evaluation [28-31].

The decision-making steps are as follows:

(1) If there are $m$ alternative suppliers and $n$ evaluation indexes (also called factor or criterion), then the initial judgment matrix reads as follows:

$$
Y=\left[y_{i j}\right]_{m * n}(i=1,2, \ldots, m ; j=1,2, \ldots, n) .
$$

(2) The initial judgment matrix is normalized, and the normalized matrix reads as follows:

$$
Z=\left[z_{i j}\right]_{m * n}(i=1,2, \ldots, m ; j=1,2, \ldots, n) .
$$

(3) According to the normalized matrix $Z=\left[z_{i j}\right]_{m * n}$, the entropy of the $j$ th evaluation index reads as follows:

$$
E_{j}=-k \sum_{i=1}^{m} z_{i j} * \ln z_{i j}
$$

In equation (9), $k=1 / \ln m>0, E_{j}>0$. If the $j$ th evaluation index of the alternative suppliers is the same, then $y_{1 j}=y_{2 j}=\cdots=y_{m j}$ and $y_{i j}=1 / m$, and at this time, the entropy $E_{j}$ has the maximum value $E_{j}=1$.

(4) The mutation coefficient and weight of the jth evaluation index calculate as follows:

$$
\begin{aligned}
G_{j} & =1-E_{j}(j=1,2, \ldots, n), \\
w_{j} & =\frac{G_{j}}{\sum_{j=1}^{n} G_{j}}(j=1,2, \ldots, n) .
\end{aligned}
$$

In equation (10) and (11), $G_{j}$ and $w_{j}$ represent the value of mutation coefficient and weight of the $j$ th evaluation index, respectively.

(5) According to the weight of each index calculated by equations (8) and (9), the weighted normalized matrix $P=\left(p_{i j}\right)_{m * n}$ calculates as follows:

$$
p_{i j}=w_{j} z_{i j}(i \in m, j \in n) .
$$

(6) The calculation of positive and negative ideal solutions $P^{+}$and $P^{-}$reads as follows:

$$
\begin{aligned}
& P^{+}=\left\{p_{1}^{+}, p_{2}^{+}, \cdots, p_{n}^{+}\right\}=\left\{\max _{i} p_{i j}\left|j \in T_{1}, \min _{i} p_{i j}\right| j \in T_{2}\right\}, \\
& P^{-}=\left\{p_{1}^{+}, p_{2}^{+}, \cdots, p_{n}^{+}\right\}=\left\{\max _{i} p_{i j}\left|j \in T_{2}, \min _{i} p_{i j}\right| j \in T_{1}\right\} .
\end{aligned}
$$

In equation (13) and (14), $T_{1}$ represents the benefit evaluation index and $T_{2}$ denotes the cost evaluation index, which corresponds to the proposed cost, quality, and service. Specifically, the cost evaluation index corresponds to the cost, while the benefit evaluation index corresponds to the quality and service.

(7) The distances between the suppliers and the positive ideal solution $P^{+}$and between the suppliers and the negative ideal solution $P^{-}$calculate as follows:

$$
\begin{aligned}
& d_{i}^{+}=\sqrt{\sum_{j}^{n}\left(p_{i j}-P^{+}\right)^{2}}(i=1,2, \ldots, m), \\
& d_{i}^{-}=\sqrt{\sum_{j}^{n}\left(p_{i j}-P^{-}\right)^{2}}(i=1,2, \ldots, m) .
\end{aligned}
$$

(8) The degree of fit between the evaluation suppliers and the positive ideal solution is calculated, and the best supplier is selected, as shown in the following:

$$
C_{i}^{+}=\frac{d_{i}^{-}}{d_{i}^{+}+d_{i}^{-}} .
$$

The greater the degree of fit is, the more reliable the supplier is, and the more worthy of selection is. On the contrary, the smaller the degree of it is, the less reliable the supplier is, and the less worthy of selection is. Finally, the best supplier is selected according to the sorting size.

2.4. Case Simulation. Due to the fierce and dynamic market competition, the form of competition among investors has also changed and is gradually inclined to the supply chain. Lv et al. proposed that compared with joint venture suppliers, self-operated retailers had higher retail prices and lower unit operating costs, thus, lower operating costs [32]. When investors make decisions, they should consider supply chains management, such as evaluation and selection, commodity design, commodity quality, commodity sales, and commodity transportation, of which the evaluation and selection of suppliers are the most important, and it is also the key link of the whole decision-making. A proper supplier selection can save costs and benefits the follow-up development. Therefore, accurate, objective, comprehensive, and reliable evaluation and decision-making of suppliers will promote the healthy development of the investment project and obtain the maximum benefits.

Given various practical problems related to multicriteria decision-making, here, it is assumed that an investment 
enterprise will invest in a retail project, and there are three suppliers $\mathrm{A}, \mathrm{B}$, and $\mathrm{C}$ to choose from. BN-based TOPSIS normal stochastic multicriteria decision-making method can analyze and evaluate these suppliers, thereby finding the best supplier. The experimental results can evaluate the proposed method's reliability and effectiveness in practical application. Firstly, according to the conditional probability distribution determined by the expert knowledge and the prior distribution of various evaluation indexes of each supplier, the $\mathrm{BN}$ simulation analysis is carried out using Netica. Through probability inference, the probability of True cost, quality, and service of each supplier is obtained, and the percentage probability is taken as the reliability score of the supplier. Secondly, these suppliers are analyzed and evaluated based on TOPSIS normal stochastic multicriteria decision-making method. Finally, the accuracy of the results is verified under the comparative analysis of references.

\section{Results and Analysis}

3.1. Supplier Evaluation Results Based on BN. It is assumed that investors have the following requirements when choosing suppliers: (1) Cost. The purchase cost is controlled within 20,000 RMB, the distribution cost is controlled within $2,000 \mathrm{RMB}$, and the wastage cost is controlled within 1,000 RMB. (2) Quality. The damage rate of new products is less than $3 \%$, the damage rate of inventory products is less than $3 \%$, and the damage rate of recycled products returned to the factory is less than $4 \%$. (3) Service. The satisfaction feedback of presales service shall be at least $95 \%$, the satisfaction feedback of the in-sale service shall not be less than $85 \%$, and the satisfaction feedback of after-sales service shall not be less than $70 \%$. The evaluation indexes of each supplier are determined by expert interviews and field investigation, as shown in Table 2.

The Netica is employed to analyze the evaluation index of each supplier, and the obtained statistical data are used for the reliability evaluation of the proposed method. The details are shown in Figure 6-8 (only the score of supplier A is shown).

The cost, quality, and service evaluation scores of the remaining two suppliers $\mathrm{B}$ and $\mathrm{C}$ are obtained according to the same operation and all scores are summarized in Table 3:

\subsection{TOPSIS Normal Stochastic Multicriteria Decision-Making} Method. Given the above-mentioned supplier selection decision problem, TOPSIS normal stochastic multicriteria decision-making method is used for sorting:

(1) Table 3 reveals that a judgment matrix is constructed to make a preliminary judgment on the evaluation of each supplier. The expression of the preliminary judgment matrix reads as follows:

$$
Y=\left[\begin{array}{lll}
82.3 & 89.8 & 85.7 \\
83.4 & 85.2 & 87.8 \\
76.9 & 90.3 & 81.5
\end{array}\right] .
$$

(2) According to equation (8), the initial judgment matrix $Y$ is normalized by column, and the expression of the normalized matrix $Z$ reads as follows:

$$
Z=\left[\begin{array}{ccc}
0.86 & 0.90 & 0.67 \\
1 & 0 & 1 \\
0 & 1 & 0
\end{array}\right] .
$$

(3) According to equations (9) to (17), TOPSIS calculation is performed using MATLAB to calculate the fit degree of alternative suppliers to positive ideal solution $p^{+}$and negative ideal solution $p^{-}$, as shown in Table 4.

Table 4 demonstrates the fitting degree of participating suppliers A, B, and $C$ with the positive ideal solution. According to their size, the order is $B>C>A$. Thus, supplier $B$ has the best fitting degree and is the best choice for investment.

Considering the verification of the reliability and accuracy of the proposed method, other methods are chosen based on the literature review [33] and used for comparative analysis. According to the five optional suppliers and nine evaluation indexes mentioned in the literature, three suppliers are selected respectively, and the three indexes (buying price, inventory level, and delivery reliability) are specifically analyzed. Generally, the buying price plays a decisive role in reducing the investment cost and improving the competitiveness of investors; the inventory level of the supplier can reflect the hardware strength of the supplier and the production efficiency of the market demand and can judge whether it can meet the demand of investors quickly; finally, the reliability of delivery shows the supplier's ability to deliver timely. When making decisions, investors have to consider carefully. The stronger the reliability is, the more reassuring the investor is, and the more secure the development of the investment project is.

Subsequently, the selected data are sorted out. The three candidate suppliers are set as $Q=\left\{Q_{1}, Q_{2}, Q_{3}\right\}$, and the three evaluation criteria are set as $P=\left\{P_{1}, P_{2}, P_{3}\right\}$. Here, $P_{1}, P_{2}, P_{3}$ represent buying price, inventory level, and delivery reliability, respectively. Three decision-making experts with equal decision-making authority are invited for evaluation, and the evaluation results of each evaluation index of each supplier follow the normal random distribution. Table 5 is the decision matrix, and the best supplier is selected.

Regarding the decision-making problem, the calculation process is as follows:

(1) According to the decision matrix of normal random variables given in Table 5, the optimal solution and the worst solution read as follows:

Optimal solution: $C^{+}:\left\{N\left(462,112^{2}\right) N\left(171,32^{2}\right) N\right.$ $\left.\left(15,6^{2}\right)\right\}$.

Worst solution: $C^{-}:\left\{N\left(449,131^{2}\right) N\left(168,37^{2}\right) N\right.$ $\left.\left(5,7^{2}\right)\right\}$.

(2) According to equations (15) and (16), the distances are calculated between the alternative solution and 
TABle 2: Prior distribution of evaluation indexes of each participating supplier.

\begin{tabular}{lccc}
\hline Evaluation index & \multicolumn{3}{c}{ Participating supplier } \\
& $A$ & $\left(19500,200^{2}\right)$ & $\left(18500,200^{2}\right)$ \\
Purchase cost $C_{1}$ & $\left(19000,200^{2}\right)$ & $\left(1900,100^{2}\right)$ & $\left(1800,100^{2}\right)$ \\
Distribution cost $C_{2}$ & $\left(1800,100^{2}\right)$ & $\left(900,10^{2}\right)$ & $\left(850,10^{2}\right)$ \\
Wastage cost $C_{3}$ & $\left(800,10^{2}\right)$ & $(200,5)$ & $(180,5)$ \\
New product quality $Q_{1}$ & $(150,4)$ & $(300,8)$ & $(200,7)$ \\
Inventory product quality $Q_{2}$ & $(100,2)$ & $(120,4)$ & $(0.95,0.05)$ \\
Recycled products quality $Q_{3}$ & $(100,3)$ & $(0.98,0.02)$ & $(0.85,0.15)$ \\
Presale service $S_{1}$ & $(0.95,0.05)$ & $(0.90,0.10)$ & $(0.75,0.25)$ \\
In-sale service $S_{2}$ & $(0.85,0.15)$ & & $(0.30)$ \\
After-sale service $S_{3}$ & $(0.70,0.30)$ & & \\
\hline
\end{tabular}

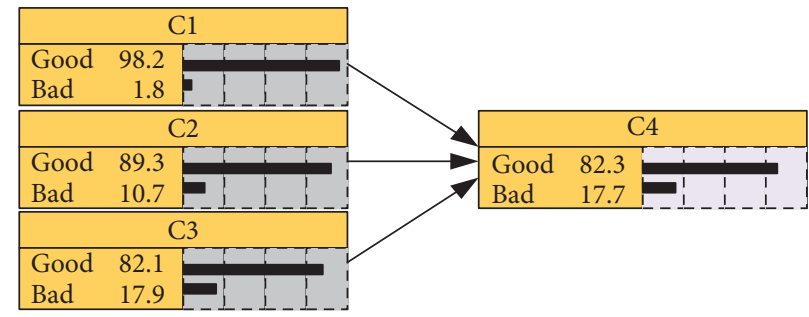

Figure 6: Cost evaluation score of supplier A.

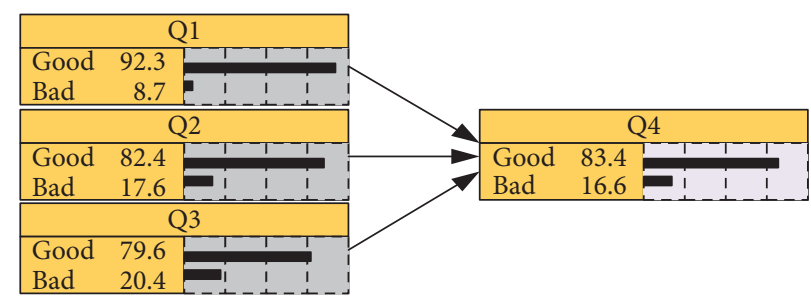

FIGURE 7: Quality evaluation score of supplier B.

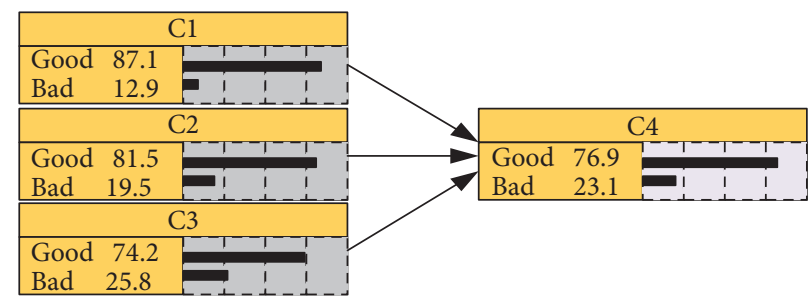

FIgURE 8: Service evaluation score of supplier A.

TABLE 3: Summary of reliability score of each supplier evaluation index.

\begin{tabular}{lccr}
\hline \multirow{2}{*}{ Evaluation index } & \multicolumn{3}{c}{ Participating supplier } \\
& $A$ & $B$ & C \\
\hline Cost & 82.3 & 89.8 & 85.7 \\
Quality & 83.4 & 85.2 & 87.8 \\
Service & 76.9 & 90.3 & 81.5 \\
\hline
\end{tabular}

the criterion of the optimal solution and between the alternative solution and the criterion of the worst solution, as shown in Figures 9 and 10.
(3) The distance $D_{i}^{+}$from each solution to the optimal solution, and the distance $D_{i}^{-}$from each solution to the worst solution are calculated. 
TABLE 4: The best fit degree of all participating suppliers.

\begin{tabular}{lccr}
\hline & & Participating supplier & $C$ \\
& $A$ & $B$ & 0 \\
Positive ideal solution & 0.175 & 0.132 & 0.027 \\
Negative ideal solution & 0 & 1 & 0.126 \\
Fitting degree & 0 & 0.831 \\
\hline
\end{tabular}

TABLE 5: Normal random multicriteria decision matrix.

\begin{tabular}{lccr}
\hline Supplier & \multicolumn{1}{c}{ Factors } & $P_{3}$ \\
\hline$Q_{1}$ & $P_{1}$ & $N\left(171,37^{2}\right)$ & $N\left(5,7^{2}\right)$ \\
$Q_{2}$ & $N\left(449,131^{2}\right)$ & $N\left(168,32^{2}\right)$ & $N\left(10,7^{2}\right)$ \\
$Q_{3}$ & $N\left(454,112^{2}\right)$ & $N\left(170,37^{2}\right)$ & $N\left(15,6^{2}\right)$ \\
\hline
\end{tabular}

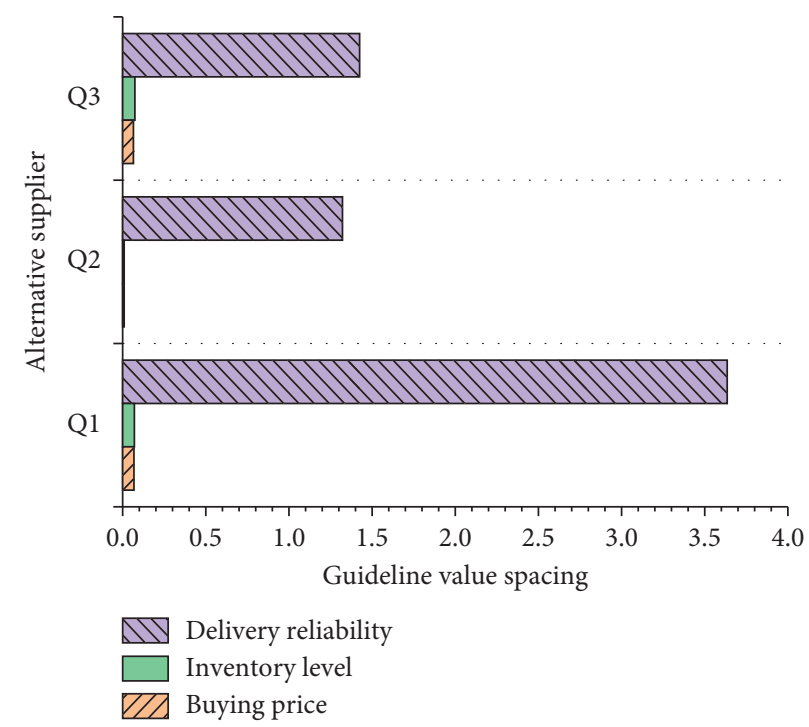

Figure 9: Distance between evaluation indexes of alternative solutions and the optimal solution.

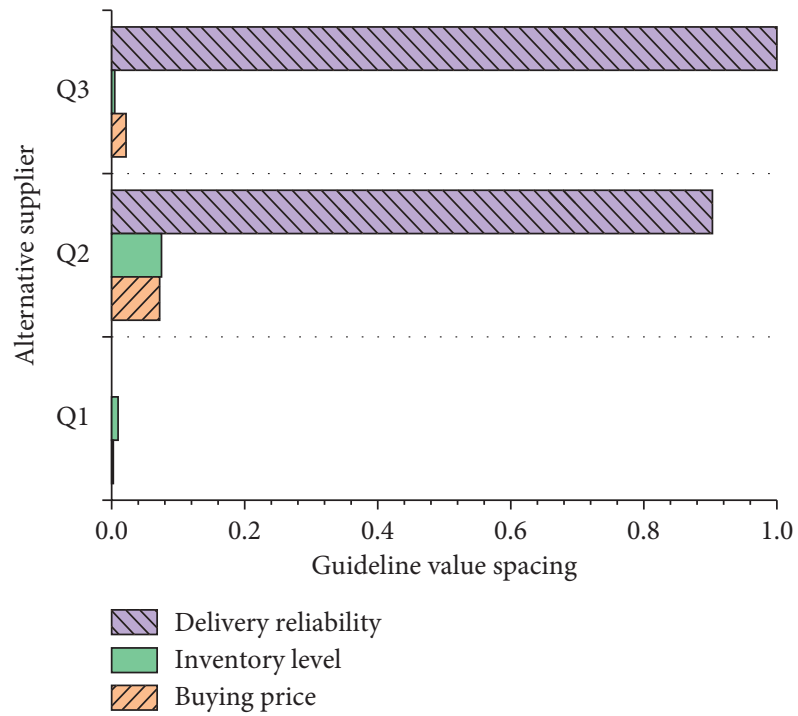

FIGURE 10: Distance between evaluation indexes of alternative solutions and the worst solution. 


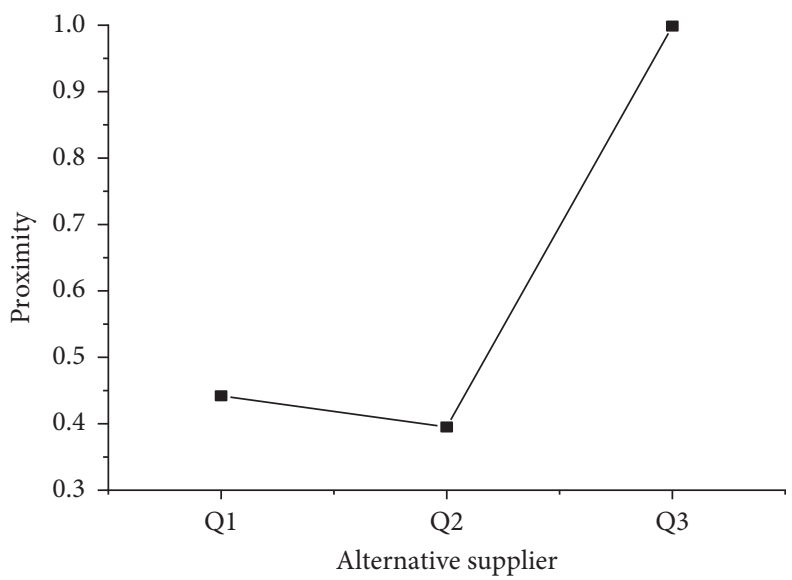

FIGURE 11: Closeness of the alternatives to the optimal one $\widetilde{C}_{i}$.

$D_{1}^{+}=0.516528, D_{2}^{+}=0.146973$, and $D_{3}^{+}=0.173309$.

$D_{1}^{-}=0.001499, D_{2}^{-}=0.116417$, and $D_{3}^{-}=0.113148$.

(4) The closeness of each solution to the optimal solution is calculated by equation (17), and the solutions are sorted, as shown in Figure 11.

According to the closeness of each solution, the ranking result of alternative solutions in Figure 11 is $Q 2<\mathrm{Q} 1<\mathrm{Q} 3$; that is, Q3 is the best supplier. The calculation results are consistent with the literature results, which shows that the method is more reliable and effective in helping investors make decisions.

\section{Conclusion}

Here, the normal random variables are chosen to deal with the stochastic multicriteria decision-making problem in which the criteria are a normal random variable and the weight of the criteria is determined, and the distances between the criteria of the alternatives and the optimal and the worst alternatives are found out. Meanwhile, product cost, product quality, and product service are selected as evaluation indexes, and a supplier evaluation model is built based on the BN concept. After expert evaluation, the obtained evaluation information is integrated. Then, based on TOPSIS normal stochastic multicriteria decisionmaking method, the most suitable supplier is selected under the comparison of the fit degree between each supplier and the optimal and the worst solution. Here, case analysis on the retail industry is conducted through the simulation experiment. The results suggest that in terms of decision-making for optimal supplier selection in the retail industry, the BN model can truly feed back the product quality, product cost, and product service of each supplier and fully consider the diversity of their behavior; the normal stochastic multicriteria decision-making method based on TOPSIS can select the optimal suppliers for investors; under complex supplier market, BN TOPSIS normal stochastic multicriteria decision-making method has strong logic and efficiency and is easy to operate; it has a high value in practical applications. Regarding the legislative proposal, currently, project investment decisionmaking can rely on nothing but mainly based on the judgment of policy management and other practical problems. Here, it is argued that the legislation should be sped up for project investment decision-making; the accountability system should be implemented at an individual level. The shortcomings and proposed suggestions are summarized: (1) Only three supplier evaluation indexes (product cost, product quality, and product service) are selected, which is not comprehensive enough. In the follow-up study, the supplier's technology, environmental protection, and flexibility will be added to perfect the evaluation system; (2) The proposed stochastic multicriteria decision-making method is about selective ranking. In the follow-up study, the classification problem in stochastic multicriteria decision-making can be further explored; these stochastic multicriteria decision-making methods can be extended to more fields to enhance their practical applications.

\section{Data Availability}

The data used to support the findings of this study are available from the corresponding author upon request.

\section{Conflicts of Interest}

The authors declare that they have no conflicts of interest.

\section{References}

[1] H. L. Zhang, "Research on investment project decisionmaking," Economic Research Guide, vol. 444, no. 22, pp. 53-54, 2020.

[2] H. B. Li, "Discussion on decision analysis and process management of enterprise investment projects," Fortune Times, vol. 179, no. 4, pp. 165-167, 2020.

[3] X. L. Cheng, "Analysis on the influence factors of government project investment and thinking on improving the comprehensive benefits of investment," China Engineering Consulting, vol. 241, no. 6, pp. 89-92, 2020.

[4] M. Q. Liao, "Research on the existing problems and countermeasures of the agent construction system management of 
government investment projects," Construction Supervision, vol. 255, no. 9, pp. 20-23, 2020.

[5] J. W. Gao and F. J. Guo, "Intuitionistic fuzzy stochastic multicriteria decision-making method based on improved prospect theory," Control and Decision, vol. 34, no. 2, pp. 96-103, 2019.

[6] G. O. Odu, "Weighting methods for multicriteria decisionmaking technique," Journal of Applied Sciences \& Environmental Management, vol. 23, no. 8, pp. 1449-1457, 2019.

[7] M. Keshavarz Ghorabaee, M. Amiri, and E. K. Zavadskas, "Stochastic EDAS method for multicriteria decision-making with normally distributed data," Journal of Intelligent and Fuzzy Systems, vol. 33, no. 3, pp. 1627-1638, 2017.

[8] F. Xiao, "EFMCDM.: Evidential fuzzy multicriteria decision making based on belief entropy," IEEE Transactions on Fuzzy Systems, vol. 28, no. 7, pp. 1477-1491, 2019.

[9] C. Novis, "Bayes' theorem," South African Ophthalmology Journal, vol. 13, no. 4, pp. 34-35, 2018.

[10] G. Selvachandran, S. G. Quek, and F. Smarandache, "An extended technique for order preference by similarity to an ideal solution (TOPSIS) with maximizing deviation method based on integrated weight measure for single-valued neutrosophic sets," Symmetry, vol. 10, no. 7, p. 236, 2018.

[11] J. J. Wu, "Research on the characteristics of the selection and decision-making of venture capital projects," Management and Technology of Small and Medium-sized Enterprises, vol. 8, no. 1 , pp. $172-173+179,2020$.

[12] H. Y. Wei, "Research on investment project decision-making based on financial perspective," Operator, vol. 34, no. 1, pp. 50-51, 2020.

[13] Y. Li, "Research on the legal issues of project financing-from the perspective of private equity financing," China Economic and Trade Guide, vol. 971, no. 6, pp. 179-180, 2020.

[14] J. X. Ye, "Research on optimization of internal control of infrastructure PPP projects," Shangxun, vol. 201, no. 11, pp. 174-175, 2020.

[15] J. Liu, "“Government investment ushered in the first administrative regulation "image project" is expected to come to an end," Decision Exploration, vol. 617, no. 6, pp. 36-37, 2019.

[16] Z. C. Sun, "Analysis of plague prevention and control process," Mathematical Modeling and Its Applications, vol. 9, no. 1, pp. 9-14, 2020.

[17] X. X. Liu, R. H. Lu, and F. W. Zhu, "Evaluation and analysis of the implementation effect of the rice fertilizer quota system in Zhejiang Province," Zhejiang Agricultural Sciences, vol. 61, no. 10, pp. 7-9, 2020.

[18] F. M. Ye, C. Ma, and Z. Hou, "Morphological diversity analysis of ornamental characters of different kinds of cut chrysanthemum," Liaoning Agricultural Sciences, vol. 1, no. 2, pp. 7-11, 2020.

[19] P. R. Pang, "Application of sigma normal distribution to quality cost control of offshore petroleum engineering projects," Business Intelligence, vol. 1, no. 10, pp. 188-189, 2020.

[20] Y. Su, "The application of normal distribution in daily life," guide," Journal of Science \& Technology Economy, vol. 713, no. 15, p. 163, 2020.

[21] L. Zhou, "Portfolio optimization from the perspective of tail risk," Statistics and Information Forum, vol. 35, no. 6, pp. 80-88, 2020.

[22] M. Q. Jia and Y. D. Cheng, "Location selection of logistics storage nodes based on fuzzy multicriteria decision-making method," Journal of Xiang nan University, vol. 40, no. 2, pp. 32-36, 2019.
[23] C. Wang and J. Li, "Project investment decision based on VIKOR interval intuitionistic fuzzy set," Journal of Intelligent and Fuzzy Systems, vol. 1, pp. 1-9, 2021.

[24] E. S. Ari and C. Gencer, "The use and comparison of a deterministic, a stochastic, and a hybrid multiple-criteria decision-making method for site selection of wind power plants: an application in Turkey," Wind Engineering, vol. 44, no. 1, pp. 60-74, 2020.

[25] D. Zindani, S. R. Maity, and S. Bhowmik, "Decision-making tools for optimal material selection: a review," Journal of Central South University, vol. 27, no. 3, pp. 629-673, 2020.

[26] S. Lv, "Research on bayesian network's risk assessment of tunnel construction," Transportation Technology and Economy, vol. 1, no. 22, pp. 55-56, 2020.

[27] R. J. Zhao, Y. F. Long, and K. Zhao, "Application of Bayesian network in water conservancy projects," Northeast Water Resources and Hydropower, vol. 38, no. 4, pp. 62-65, 2020.

[28] M. Aghaei and I. Yeoman, "Valuation of the Hamrah-e-Aval brand based on brand valuation models using Topsis multicriteria decision-making model," Journal of Revenue and Pricing Management, vol. 20, no. 7, pp. 42-53, 2021.

[29] J. X. Wang, S. E. Zhao, and Q. Z. Yang, "Vehicle collision risk assessment based on the combination weighting TOPSIS method of game theory," Science Technology and Engineering, vol. 20, no. 8, pp. 3315-3322, 2020.

[30] P. Q. Li, W. Q. Xue, and X. X. Tang, "A method for evaluating the importance of users in photovoltaic user groups based on the TOPSIS method," Journal of Hunan University, vol. 324, no. 12, pp. 122-128, 2020.

[31] A. Ishak and L. Wan, "Analysis of fuzzy AHP-TOPSIS methods in multi-criteria decision making: literature review," IOP Conference Series: Materials Science and Engineering, vol. 1003, no. 1, Article ID 012147, 2020.

[32] Z. Lv, D. Chen, and J. Li, "Novel system design and implementation for the smart city vertical market," IEEE Communications Magazine, vol. 59, no. 4, pp. 126-131, 2021.

[33] Q. Gao and G. D. Li, "Research on supplier selection model based on improved TOPSIS method," Hebei Industrial Science and Technology, vol. 184, no. 6, pp. 10-15, 2020. 